\title{
Mother-child interaction and the development status of children who have been accidentally poisoned
}

\author{
Ganime Ayar ${ }^{1 \oplus}$, Tülin Köksal ${ }^{1}$, Funda Kurt ${ }^{1}$, Aysun Kara Uzun ${ }^{1}$, \\ Bahar Çuhacı Çakır ${ }^{1}$, Birgül Bayoğlu², Sıddıka Songül Yalçın \\ ${ }^{1}$ Ankara Children's Hematology Oncology Training and Research Hospital, University of Health Sciences, Ankara; ${ }^{2}$ Unit of Child \\ Development, Bayindır Hospital, Ankara; ${ }^{3}$ Division of Social Pediatrics, Hacettepe University Faculty of Medicine, Ankara, Turkey.
}

\begin{abstract}
Positive parent-child interaction, in particular bond between mother and child, is important for the mental and behavioral development of children. The aim of this study was to evaluate both mother-child interactions as well as the developmental status of children admitted to the pediatric emergency department with accidental poisoning using Parenting Interactions with Children: Checklist of Observations Linked to Outcomes tool (PICCOLO) and Denver Developmental Screening Test-II (DDST-II). Children between ages 1 to 5 years who were admitted to the emergency department with accidental poisoning were included in the study alongside a control group selected from healthy volunteers. A ten-minute video recording was obtained both for the case and control groups, while the mother and her child played together in a separate room. The interaction of mother-infant pair was assessed using the PICCOLO tool. The children's development was examined using the DDST-II. The video recordings of 115 children ( $n=65$ in the case group and $n=50$ in the control group) were evaluated. A high score of PICCOLO-teaching domain ( $\geq 9$ points) was associated with a 3.3-fold increase in terms of risk of poisoning [ $\mathrm{p}<0.05$, at $95 \%$ confidence interval (CI) of 1.34-8.37]. Multivariable analysis revealed that the PICCOLO-teaching domain was a significant factor. A high proportion of cases had either abnormal or questionable DDST-II scores $(\mathrm{p}<0.05)$. In order to improve the bond between mother and child, drug poisoning prevention training must be meticulously provided to both mothers and children alike. Developmental assessments of these children as a holistic approach also should not be forgotten.
\end{abstract}

Key words: child, intoxication, mother-child interaction.

Poisoning is one of the most common medical problems that children are exposed to. ${ }^{1}$ It is more so encountered in children under 5 years of age. Accidental poisoning accounts for $67.4 \%$ of all poisoning cases, of which mortality accounts for $2 \%$ of cases. Among these, the mortality rate of drug-related poisoning cases is $1.3 \% .^{2}$ These rates indicate the importance of preventing accidental poisoning. It is certain that classical measures are crucial, and that they should be

Ganime Ayar

ganimeayar@gmail.com

Received 6th March 2019; revised 3rd April 2019; accepted 7th May 2019

Only part of the results (preliminary study) were presented as a poster presentation at the 15th WAIMH Conference (World Association for Infant Mental Health), May 29-June 2, 2016, Prague, Czech Republic (P551 ID 706). implemented in order to prevent poisoning. ${ }^{3}$ In addition, it is well documented that parental behavior influences a child's health and their social outcomes. Positive parenting practices are associated with the positive social skills of children; moreover, good parental practices can protect children from an unfavorable outcome. ${ }^{4}$ The basis of a healthy mother-child relationship depends upon how the mother behaves, which in turn shapes personality traits of the child. The quality of this interaction with the child determines how children ultimately behave. ${ }^{5-7}$ The literature fails to show whether there is any relationship between accidental poisoning and the bond between parent and child. Therefore, we set out to evaluate this, as well as assess the developmental status in children presented with accidental poisoning. 


\section{Material and Methods}

After approval from the Institutional Ethics Committee (Ankara Child Health and Diseases Hematology Oncology Training and Research Hospital, protocol code: 2015-017), we prospectively included asymptomatic children under the age of 5 and who were admitted to the emergency department between July 2015 and June 2016 due to accidental poisoning or accidental drug intake. The mother-child bond was assessed using a tool known as the Parenting Interactions with Children: Checklist of Observations Linked to Outcomes (PICCOLO). The developmental steps of both the healthy as well as poisoned children were assessed using the Denver Developmental Screening Test II (DDST-II). The control group comprised of healthy children within the same age range who were admitted to the outpatient clinic. Those who were enrolled in both groups included children with a gestational age of $>37$ weeks, a birth weight of $>2500 \mathrm{~g}$, and no background of any genetic syndromes, neurological diseases, or other chronic diseases. Parents were informed about the study, and written informed consent was obtained. Those who did not give permission or consent to be videotaped were excluded from the study.

The characteristics of the children, their families, and the details relating to the poisoning events were learned through a questionnaire developed by the researchers.

A room filled with children's toys in which the mother and the child could play together was provided both to the control group as well as the poisoning cases. The same environment and same toys were used for all of the participating children. Ten-minute videotapes were made while the mothers played with their children. After filming, DDST-II was performed on the children. Then, the mothers were provided education on child development and care depending on their respective scores.

PICCOLO is a scoring system that evaluates a healthy child-parent interaction and identifies problems, that also gives anticipatory guidelines. The video footage was evaluated using the PICCOLO tool created by Roggman et $\mathrm{al}^{8}{ }^{8}$ with a checklist of 29 observable behaviors in order to assess the parenting interaction in four domains: affection, responsiveness, encouragement, and teaching. Each of the four PICCOLO domains included seven to eight items of observable parenting behavior, each with a short label and a more detailed description of the behavior. Each item was scored as 0 (absent, no behavior was observed), 1 (barely, brief, minor, or emerging behavior was observed), or 2 (clearly, definite, strong, or frequent behavior was observed). A score of 42 and above was considered to be a high for PICCOLO-total, 11 and above was considered to be high for PICCOLO-affection, PICCOLOresponsiveness, and PICCOLO-encouragement, and 9 and above was considered to be high for PICCOLO-teaching. It has been translated into Turkish and validated. ${ }^{9}$ We used the Turkish version of the tool. ${ }^{9}$

\section{Statistical analysis}

The sample size calculation for the present study was performed using G*Power V3.1.9. Given that no study of a similar nature presently exists in the literature, the effect size could not be calculated. In taking the mean effect size as suggested by Cohen as $0.5^{10}$ with a $5 \%$ error and $80 \%$ power, the sample size required in the independent groups was determined to be 51 for each group and 102 in total. Statistical analysis was performed using IBM SPSS Statistics for Windows V 22.0 (IBM Corp., Armonk, NY, USA). The scores were compared to the predetermined values, and the mean scores were calculated. The chi-square and Mann-Whitney U tests were used for the comparison of data upon seeking normality. Multiple logistic regression analysis was performed after controlling gender, children's age, mother's age range, mother's employment status, mother's educational level being of high school or higher, being the first child, presence of a child aged $\leq 5$ years at home, and number of households being $\geq 5$. A $p$ value of $\leq 0.05$ was considered as being statistically significant. 


\section{Results}

The video footage of all 115 children was examined, and the PICCOLO scores were calculated. Baseline variables are mentioned in Table I. There were no significant differences between the case and control groups in terms of gender and age of the children, the mother's age, level of educational, employment status $\backslash$ being the first child, having a sibling or a child under the age of 5 years at home and whether the child is being cared for at home or attending kindergarten or not (Table I).

Analgesics, antipyretics, and decongestants ranked first at a rate of $29.9 \%$ among the drugs ingested accidentally. Two cases involved the ingestion of more than one drug. Of these cases,
$75 \%$ had ingested the drugs within their own homes (Table II).

The relationship between accidental drug ingestion and the PICCOLO scores for each domain alongside the PICCOLO-total score is summarized in Table III. A high score of PICCOLO-teaching domain ( $\geq 9$ points) was associated with a 3.3-fold increase in the risk of poisoning $[\mathrm{p}<0.05$, at $95 \%$ confidence interval (CI) of 1.34-8.37]. However, high PICCOLOaffection scores, high responsiveness, and high encouragement domain, and PICCOLO total scores were not significant $(p>0.05)$. Multivariable analysis revealed that PICCOLOteaching domain was a significant factor after adjusting the children's gender and age groups, the mother's age and level of education, birth

Table I. Comparison of the case and control groups in terms of general characteristics.

\begin{tabular}{lccc}
\hline Characteristics & Case Group (n=65) & Control Group $(\mathrm{n}=50)$ & $\mathrm{p}$ \\
\hline Children's gender, male & $\mathrm{n}(\%)$ & $\mathrm{n}(\%)$ & 0.896 \\
Children's age $\leq 24$ months & $33(50.8)$ & $26(52.0)$ & 0.373 \\
Birth order, being the first child & $25(38.5)$ & $26(52.0)$ & 0.200 \\
Presence of a sibling & $26(40.0)$ & $26(52.0)$ & 0.701 \\
Presence of a child aged $<5$ years at home & $38(58.5)$ & $31(62.0)$ & 0.557 \\
Number of households $\geq 5$ & $16(24.6)$ & $10(20.0)$ & 0.906 \\
Mother's age $\leq 24$ years & $24(36.9)$ & $19(38.0)$ & 0.774 \\
Mother's educational level, high school or higher & $17(26.2)$ & $11(22.0)$ & 0.106 \\
Mother as the caregiver & $24(36.9)$ & $26(52.0)$ & 0.137 \\
Mother's employment status, employed & $60(92.3)$ & $41(82.0)$ & 0.163 \\
\hline
\end{tabular}

Table II. Data on poisoning.

\begin{tabular}{lc}
\hline Parameters & $\mathrm{n}(\%)$ \\
\hline Drug taken & \\
Analgesic, antipyretic, decongestant & $20(29.9)$ \\
Non-corrosive chemical substance or methyl alcohol & $9(13.4)$ \\
Antipsychotic, antiepileptic & $6(9.0)$ \\
Iron preparation & $4(6.0)$ \\
Insecticide & $3(4.5)$ \\
Other & $25(37.3)$ \\
Total (two cases had more than one poison ingested) & $67(100)$ \\
\hline Place of poisoning & \\
Home & $49(75.4)$ \\
Outside home & $16(24.6)$ \\
\hline
\end{tabular}


Table III. Relationship between drug ingestion and PICCOLO scores.

\begin{tabular}{lcccc}
\hline & $\begin{array}{c}\text { Univariable analysis } \\
\text { OR }(95 \% \mathrm{CI})\end{array}$ & $\mathrm{p}$ & $\begin{array}{c}\text { Multivariable } \\
\text { analysis* OR (95\% CI) }\end{array}$ & $\mathrm{p}$ \\
\hline PICCOLO-Affection $(\geq 11$ points) & $0.68(0.18-2.61)$ & 0.580 & $0.59(0.14-2.34)$ & 0.450 \\
PICCOLO-Responsiveness $(\geq 11$ points) & $1.89(0.57-6.26)$ & 0.298 & $2.27(0.61-8.46)$ & 0.221 \\
PICCOLO-Encouragement $(\geq 11$ points) & $1.80(0.49-6.58)$ & 0.373 & $1.32(0.33-5.24)$ & 0.696 \\
PICCOLO-Teaching $(\geq 9$ points) & $3.35(1.34-8.37)$ & 0.010 & $3.22(1.17-8.80)$ & 0.023 \\
PICCOLO-Total $(\geq 42$ points) & $1.01(0.22-4.54)$ & 0.983 & $1.66(0.33-8.17)$ & 0.533 \\
\hline
\end{tabular}

CI: confidence interval, DDST-II: Denver Developmental Screening Test II, OR: odds ratio.

*Adjusted for gender, children's age, mother's age range, mother's employment status, mother's educational level being of

high school or higher, being the first child, presence of a child aged $\leq 5$ years at home, and number of households being $\geq 5$.

order, the presence of a child at home under 5 years of age and the number of households.

A comparison of the median scores of PICCOLO for each domain alongside PICCOLO-total score between the case and control groups were summarized in Table IV. The PICCOLOresponsiveness, encouragement, teaching and PICCOLO-total scores were significantly higher in the case group. When it came to whether the PICCOLO scores were high or not between the case and control groups, there was a significant difference with the exception of the PICCOLOaffection. The frequency of an abnormal or questionable result obtained from the DDSTII was $61 \%$ in the case group, and $40 \%$ in the control group. A higher proportion of cases had abnormal DDST-II scores $(\mathrm{p}<0.05)$ (Table V).

\section{Discussion}

Previous studies have indicated that poisoning more commonly occurs due to the ingestion of medications and caustic/corrosive substances. ${ }^{11}$ Just as the literature indicates, we found that one-third of the cases were poisoned only due to medical drugs, whereas nearly half of the cases were poisoned due to a mixture of

Table IV. Comparisons of scores of PICCOLO for each domain and PICCOLO-total score between the case and control groups.

\begin{tabular}{|c|c|c|c|}
\hline PICCOLO Scores & Case Group $(\mathrm{n}=65)$ & Control Group $(n=50)$ & $\mathrm{p}$ \\
\hline PICCOLO-Affection & $12(9-13) ;[6-14]$ & 10 (7-13); [4-14] & 0.094 \\
\hline PICCOLO-Responsiveness & 13 (11-14); [5-14] & 11 (9-13); [2-14] & 0.011 \\
\hline PICCOLO-Encouragement & 12 (7.8-12); [3-14] & 10 (9-13.5); [1-14] & 0.010 \\
\hline PICCOLO-Teaching & $9(6.5-12) ;[1-15]$ & $6.5(4-10) ;[0-14]$ & 0.001 \\
\hline PICCOLO-Total & $45(36.5-51) ;[22-56]$ & 39.5 (28.8-46); [11-55] & 0.002 \\
\hline
\end{tabular}

Data is presented as median (Q1-Q3); [minimum - maximum]

Table V. Comparison of high PICCOLO scores and DDST-II between two groups.

\begin{tabular}{lcccc}
\hline & Case Group, $\mathrm{n}(\%)$ & Control Group, $\mathrm{n}(\%)$ & $\mathrm{X}^{2}$ & $\mathrm{p}$ \\
\hline PICCOLO-Affection $(\geq 11$ points) & $41(63.1)$ & $23(46.0)$ & 3.34 & 0.068 \\
PICCOLO-Responsiveness $(\geq 11$ points) & $52(80.0)$ & $30(60.0)$ & 5.53 & 0.019 \\
PICCOLO-Encouragement $(\geq 11$ points) & $44(67.7)$ & $22(44.0)$ & 6.49 & 0.011 \\
PICCOLO-Teaching ( $\geq 9$ points) & $38(58.5)$ & $14(28.0)$ & 10.59 & 0.001 \\
PICCOLO-Total $(\geq 42$ points) & $43(66.2)$ & $22(44.0)$ & 5.64 & 0.018 \\
DDST-II (Abnormal or Questionable) & $40(61.5)$ & $20(40.0)$ & 5.25 & 0.022 \\
\hline
\end{tabular}

DDST-II: Denver Developmental Screening Test II, X2: Chi-square. 
medical drugs and chemicals. Moreover, our results demonstrated that $75.4 \%$ of the cases were accidentally poisoned at home, which was also similar to the literature. ${ }^{12}$

According to the main outcomes of our study, there were no significant differences between the case and control groups in terms of mother's age, level of education, or employment status. Moreover, none of these parameters were found to be a risk factor for the occurrence of accidental poisoning among the children. Based on the outcomes of a recent study on the epidemiological characteristics of accidental poisoning during childhood revealed that children living in households where addictive substances were used and as children whose mothers' were employed (and who are not a housewife) were at higher risk for accidental poisoning. ${ }^{13}$ Another study reported that parents who were insufficient when it came to supervising their children posed a greater risk when it came to poisoning children under 6 years of age. ${ }^{14}$ The studies have mainly highlighted the critical role of parents' inattentiveness. ${ }^{15}$

The common conclusion in the studies on accidental childhood poisoning was that the necessary preventive measures should be taken, not only at a national level and but also at home, and that they should be implemented adequately in order to prevent children from accidentally poisoning themselves. ${ }^{16}$ In our study, this issue has been investigated from the perspective of parental interactions with their children. This approach is based on the fact that the behavior, action, and skills of parents while interacting with their children have been shown to be quite effective in correcting children's behavioral problems. ${ }^{17}$ Different methods such as the dependency theory, learning theory, the social learning theory all focus on the improvement of parental interactions and are targeted towards preventing child abuse and negligence. ${ }^{18}$

Evaluating how well parents interact and communicate with their children is another critical sub branch of this subject. In our study, the degree of communication between parents and children was evaluated using the PICCOLO tool, as it provides concrete data on developmental guidance between parent and infant, helps determine and organize the potential needs of both the mother and children, and encourages the strengthening communication while identifying problems. ${ }^{19-22}$ In our study, the PICCOLO scores were significantly higher among the poisoned group presented than among the control group. In particular, a high score within the domain of mother-child-teaching ( $\geq 9$ points) was associated with a 3.3-fold increase in the risk of ingested medical drugs. According to these results, the parent-child interaction was higher among the case group than among the control group. This finding was contradictory to the literature, whereby it suggests a lower level of poorer parent-child interaction in the case group. The literature suggests that family negligence, the supervision of the child by people other than parents, and parents not paying attention to dangerous activities of children at home were underlined in being some of the reasons behind the occurrence of accidental childhood poisoning. ${ }^{23}$ According to the results of our study, a high proportion of children who experienced poisoning had either abnormal or questionable DDST-II results. What is more, the PICCOLO teaching scores of mothers were higher in the group with intoxication. There might be various underlying factors behind this: a) unfavorable health problems as experienced by the child might have led to an increased amount of care by the family towards the child, b) the high interaction with their children might have led children to act more bravely, to be more inquisitive and curious, and to be more prone to taking risks, c) in considering the absence of children who showed poisoning-associated symptoms or who were seriously intoxicated within the course of the present study, it could be thought that the mother group with a high PICCOLO score had exhibited overprotective behavior, and moreover had frequently visited the hospital on suspicion of their child being poisoned. 
The fact that we performed PICCOLO after the occurrence of the poisoning event makes it difficult to completely understand the cause of this situation.

There are some strengths and limitations of the study. How mothers behave towards their children may change because they are more likely to feel guilty at the moment of poisoning. In being mindful of this, the videotapes were made prior to the patients being discharged in order to minimize bias. In addition, $10 \mathrm{~min}$ video recording is necessary to evaluate parentinfant interaction. During this long time of one on one interaction the capacity of parent about the domains of affection, responsiveness, encouragement, and teaching can become visible. There are studies in which this tool was used that have been done involving different groups, including children with developmental retardation, children from different ethnicities and low-income dyads. ${ }^{7,8,24}$ However, this study is the first of its kind to use PICCOLO for accidental poisoning cases. PICCOLO is not a tool that is able to predict the future, it cannot define any pathology in parents, it is an evaluation tool that relies on observations, and it only focuses on positive parent behavior. ${ }^{9}$

In conclusion, encouragement without adequate measures being taken towards prevention of accidents may lead to an increase in the number of accidents. In order to improve the bond and therefore interaction between parent and child, education must be provided in a meticulous manner in order to prevent poisoning accidents. In addition, it appears that poisoning conditions tend to be observed more among children with developmental delays, and therefore it is felt that their developmental status ought to be evaluated more closely as well.

\section{REFERENCES}

1. Oto Geçim N, İkincioğulları D, Harmancı N. Ulusal zehir merkezine yapılan çocukluk çağ 1 vaka başvurularının değerlendirilmesi: 5 yıllık retrospektif çalışma. Türkiye Klinikleri Pediatrik Bilimler 2006; 2: 1-4.
2. Özdemir R, Bayrakci B, Teksam Ö, Yalçın B, Kale G. Thirty-three-year experience on childhood poisoning. Turk J Pediatr 2012; 54: 251-259.

3. Kendrick D, Majsak-Newman G, Benford P, et al. Poison prevention practices and medically attended poisoning in young children: multicentre casecontrol study. Inj Prev 2017; 23: 93-101.

4. Shah R, Sobotka SA, Chen YF, Msall ME. Positive Parenting practices, health disparities, and developmental progress. Pediatrics 2015; 136: 318326.

5. Arias D, Peña M. Mother-infant face-to-face interaction: the communicative value of infantdirected talking and singing. Psychopathology 2016; 49: 217-227.

6. Hallas D, Koslap-Petraco M, Fletcher J. Socialemotional development of toddlers: randomized controlled trial of an office-based intervention. J Pediatr Nurs 2017; 33: 33-40.

7. Fuligni AS, Brooks-GunnJ.Mother-child interactions in early head start: age and ethnic differences in lowincome dyads. Parent Sci Pract 2013; 13: 1-26.

8. Roggman LA, Cook GA, Innocenti MS, Norman VJ, Christiansen K. Parenting interactions with children: checklist of observations linked to outcomes (PICCOLO) in diverse ethnic groups. Infant Ment Health J 2013; 34: 290-306.

9. Bayoğlu B, Unal Ö, Elibol F, Karabulut E, Innocenti MS. Turkish validation of the PICCOLO (Parenting Interactions with Children: Checklist of Observations Linked to Outcomes). Infant Ment Health J 2013; 34: 330-338.

10. Cohen J. Statistical Power Analysis for the Behavioral Sciences (2nd ed). New York: Lawrence Erlbaum Associates, 1988.

11. Peden MM, Oyegbite K, Ozanne-Smith J, et al. World Report on Child Injury Prevention. Chapter 6-7. Geneva, Switzerland New York, NY: World Health Organization UNICEF. 2008: 123-155.

12. Atak N, Karaoglu L, Korkmaz Y, Usubutun S. A household survey: unintentional injury frequency and related factors among children under five years in Malatya. Turk J Pediatr 2010; 52: 285-293.

13. Mansori K, Soori H, Farnaghi F, Khodakarim S, Hanis SM, Khodadost M. A case-control study on risk factors for unintentional childhood poisoning in Tehran. Med J Islam Repub Iran 2016; 30: 355.

14. Wood JN, Pecker LH, Russo ME, Henretig F, Christian CW. Evaluation and referral for child maltreatment in pediatric poisoning victims. Child Abuse Negl 2012; 36: 362-369. 
15. Pac-Kożuchowska E, Krawiec P, MroczkowskaJuchkiewicz A, et al. Patterns of poisoning in urban and rural children: a single-center study. Adv Clin Exp Med 2016; 25: 335-340.

16. İnce T, Yalçın SS, Yurdakök K. Çocukluk çağında ciddi kaza sıklığ1 ve risk faktörleri. Çocuk Sağlığ1 ve Hastalıkları Dergisi 2014; 57: 173-182.

17. Yalçın SS, Yurdakök K. Çocuklar ve ev kazaları. Hacettepe Tıp Dergisi 1999; 30: 117-124.

18. Reynolds AJ, Mathieson LC, Topitzes JW. Do early childhood interventions prevent child maltreatment? A review of research. Child Maltreat 2009; 14: 182206.

19. Vlahovicova K, Melendez-Torres GJ, Leijten P, Knerr W, Gardner F. Parenting programs for the prevention of child physical abuse recurrence: a systematic review and meta-analysis. Clin Child Fam Psychol Rev 2017; 20: 351-365.
20. Wheeler R, Ludtke M, Helmer J, Barna N, Wilson $\mathrm{K}$, Oleksiak C. Implementation of the PICCOLO in infant mental health practice: a case study. Infant Ment Health J 2013; 34: 352-358.

21. Chazan-Cohen S. Striking a positive note with the PICCOLO. Infant Ment Health J 2013; 34: 363-365.

22. Bradley RH. Strike up the band, the PICCOLO players have arrived: a commentary. Infant Ment Health J 2013; 34: 359-362.

23. Turkmenoglu Y, Gumusoglu-Aksahin B, Saritas U, ve ark. Çocukluk çağı zehirlenmelerine yeniden bakış. Okmeydanı Tıp Dergisi 2015; 31: 82-91.

24. Innocenti MS, Roggman LA, Cook GA. Using the PICCOLO with parents of children with a disability. Infant Ment Health J 2013; 34: 307-318. 